\title{
Papers
}

\section{Perceptions of good medical practice in the NHS: a survey of senior health professionals}

\author{
Allen Hutchinson, Melanie Williams, Keith Meadows, Rosaline S Barbour, Roy Jones
}

\begin{abstract}
Objectives-To categorise senior health professionals' experience with poor medical practice in hospitals and in general practice, to describe perceptions which senior NHS staff have of good medical practice, and to describe how problems of poor medical practice are currently managed.
\end{abstract}

Design-A postal questionnaire survey. The questionnaire sought perceptions of good medical practice, asked participants to characterise deviations from good practice, and to describe experience with managing poor performance at the time of the introduction of the General Medical Council (GMC) performance procedures. Setting-A range of NHS settings in the UK: hospital trusts, health authorities/ boards, local medical committees, community health councils.

Subjects-Senior health professionals involved in the management of medical professional performance.

Main measures-Perceptions of what constitutes good medical practice.

Results-Most respondents considered that persistent problems related to clinical practice (diagnosis, management, and outcome and prescribing) would require local management and, possibly, referral to the GMC performance procedures. Informal mechanisms, including informal discussion, education, training, and work shifting, were the most usual means of handling a doctor whose performance was poor. Many took a less serious view of deficiencies in performance on manner and attitude and communication, although consultation skills rather than technical skills comprised the greatest number of complaints about doctors.

Conclusions-Senior NHS professionals seem reluctant to consider persistently poor consultation skills in the same critical light as they do persistently poor technical practice. These attitudes may need to change with the implementation of clinical governance and updated guidance from the GMC on what constitutes good medical practice.

(Quality in Health Care 1999;8:213-218)

Keywords: quality improvement; medical practice; poor performance
Problems with quality of care in health services are usually multifactorial, often related to systems inadequacy or failures, commonly the responsibility of many rather than a small group or a single individual. Nevertheless, the significant contribution which a single clinician can make to a system failure, through failing to perform to an adequate standard, lies behind several of the recent policy initiatives on quality improvement in British medicine and which have been concerned with the recognition and management of doctors who do not perform to an adequate standard.

This particular type of quality of care problem is acknowledged to be an often complex and difficult process in which the outcomes can be uncertain for both doctors and patients. Nor is it only an issue afflicting doctors and their patients. Most of the other clinical professions in the UK now have regulatory bodies, and these are now all facing the challenge of balancing public and professional needs in the face of poor individual performance.

Rosenthal undertook an extensive qualitative study of the issue of "the incompetent doctor" in the NHS in the early $1990 \mathrm{~s},{ }^{1}$ in which a case study approach was used to show the types of problems met by senior NHS staff and of the effects on patient care, both in process and outcome dimensions. Prophetically highlighting the impending challenge to professional self regulation, she found that poorly performing doctors were generally only restrained when a situation became potentially catastrophic. Studying the informal mechanisms for dealing with poor performance of doctors in the NHS (used much more frequently than the formal complaint mechanisms), Rosenthal pointed to the often frustrating and unsatisfactory nature of a quality review, quasiregulatory, process which seemed to have no real sanctions.

Coincidentally, Lens and van der Wal examined the problem doctor from an international perspective, ${ }^{2}$ bringing together contributors whose work demonstrated that most developed healthcare systems have difficulties in managing doctors whose performance is poor. From his work in managing problems among hospital doctors, Donaldson identified 11 categories of personal problem, behaviour, or aspect of clinical practice which might result in the need for remedial action (box 1). ${ }^{3}$

Similar forms or causes of problem practice have been identified in countries such as the Netherlands in specialist practice, ${ }^{4}$ and, as in 
- Poor attitude and disruptive behaviour

- Doubts about clinical judgment and competence

- Ill health

- Extreme workaholic tendencies

- Difficulty with personal behaviour and lifestyle

- Poses a specific health hazard

- Stress

- Lack of commitment to duties

- Dishonesty

- Disorganised practice

- Poor communication

Box 1 Categories requiring remedial action. Adapted from: Donaldson LF. Doctors With Problems in a Hospital Workforce.

the UK, other countries have begun to put in place regulations to contain poor practice. ${ }^{56}$ Not all regulatory mechanisms have proved successful.

\section{The General Medical Council's role in self regulation}

The General Medical Council (GMC) is the UK institution responsible for the registration and regulation of doctors. During recent years it has issued increasingly explicit advice on the nature of good clinical practice, recently updated through Maintaining Good Medical Practice $^{8}$ and a further revision of Good Medical Practice? ${ }^{9}$ publications which are sent to all UK doctors on the GMC register. Doctors are expected to adhere to this guidance, which sets out clear good medical practice criteria for all important aspects of care, together with advice on the management of poor performance and the duties of a doctor when faced with a case of poor performance (box 2).

In particular as a doctor you must:

- Make the care of your patient your first concern

- Treat every patient politely and considerately

- Respect patients' dignity and privacy

- Listen to patients and respect their views

- Give patients information in a way they can understand

- Respect the rights of patients to be fully involved in decisions about their care

- Keep your professional knowledge and skills up to date

- Recognise the limits of your professional competence

- Be honest and trustworthy

- Respect and protect confidential information

- Make sure that your personal beliefs do not prejudice your patients' care

- Act quickly to protect patients from risk if you have good reason to believe that you or a colleague may not be fit to practise

- Avoid abusing your position as a doctor

- Work with colleagues in the ways that best serve patients' interests

Box 2 Guidance for good medical practice (taken from Good Medical Practice ${ }^{9}$ )
Alongside the guidance are the GMC performance procedures, introduced in July 1997 following the enabling legislation by parliament in $1995 .{ }^{10}$ The procedures provide the means for the GMC to assess the performance of a doctor whose practice is considered to be poor. Restrictions on registration may be placed on the doctor after a series of steps involving a knowledge based test together with a specialty specific assessment of clinical skills (box 3).

\section{Stage 1: screening}

- The GMC receives a complaint about professional performance and undertakes initial assessment

- If there is possible serious deficiency the doctor passes on to stage 2

Stage 2: assessment of performance

- Doctor agrees to, or is required to, undergo assessment

- If performance is judged deficient through assessment, the doctor passes to stage 3 and/or stage 4

Stage 3: remedial action and reassessment

- If deficiencies are remediable, the doctor takes remedial action and undergoes reassessment

Stage 4: committee on professional performance

- Committee considers cases of doctors who refuse to cooperate or whose performance fails to improve or is sufficiently deficient to be dangerous

- Available options for action include suspension of registration

Box 3 How the performance procedures work

The context in which the performance procedures were introduced is fast changing. Within a few months of the formal start of the procedures, quasiregulatory systems and management arrangements in the NHS were introduced by the government, partly in response to concerns over various tragedies related to unacceptable variations in clinical practice (for instance the high mortality rate after complex paediatric cardiothoracic surgery which has resulted in a public enquiry ${ }^{11}$ ). Now, through the concept of clinical governance, NHS chief executives of hospital trusts (and their boards and senior clinical staff) will be responsible to parliament for the quality of care in hospital. ${ }^{12}$ Additionally, there will be an assessment framework for comparing the performance of health authorities ${ }^{13}$ and hospital trusts, the introduction of mandatory clinical audit for hospital doctors, publicly available healthcare outcome results for named hospitals, and, in the future, named hospital doctor clinical audit data will be made available to doctors from the Commission for Health Improvement. ${ }^{13}$ All this adds weight to the suggestion that the environment of British medical practice has "changed utterly", ${ }^{15}$ and that there may be significant threats to the self regulation of the medical profession as a result of high profile practice failures and changes in perceptions of the role of doctors, at least in so far as policy 
Table 1 Number of respondents who had used specific informal mechanisms to handle a poorly performing doctor in the previous two years. Ranked by order of frequency (\%)

\begin{tabular}{llll}
\hline Health authority; $n=134$ & Trust; $n=182$ & Local medical committee; $n=73$ \\
\hline 1 & Informal discussion & Informal discussion & Informal: local medical committee \\
& $119(89)$ & $167(90)$ & $60(82)$ \\
2 & Informal: local medical committee & Additional education & Informal discussion \\
& $99(74)$ & $93(51)$ & $57(78)$ \\
3 & Additional education & Work shifting & Work shifting \\
& $67(50)$ & $89(49)$ & $30(41)$ \\
4 & Work shifting & 3 wise men & 3 wise men \\
& $58(43)$ & $46(25)$ & $23(32)$ \\
5 & 3 wise men & Diverting patients & Additional education \\
& $43(32)$ & $33(18)$ & $17(23)$ \\
\hline
\end{tabular}

makers are concerned. ${ }^{16}$ It is in this context of concern over clinical standards that the study reported here was undertaken, during the months after the introduction of the GMC performance procedures in July $1997 .{ }^{17}$

\section{Objectives}

The study sets out to categorise senior health professionals' experience with poor medical practice in hospitals and in general practice, to describe perceptions which senior NHS staff have of good medical practice, and to describe how problems of poor medical practice are currently managed. It forms part of a series of studies sponsored by the GMC and designed to evaluate the introduction of the GMC's performance procedures, including also an evaluation of the fairness of the internal processes of the procedures and a study of the beliefs and understanding of a national sample of doctors about good medical practice.

\section{Methods}

In November 1997 a postal survey was undertaken of senior NHS doctors and managers who were likely to have a role in the management of doctors whose performance might be considered poor. At the time of the survey these were in:

- Health authorities/boards: the statutory NHS bodies responsible for improving the health of the nation. Directors of public health, general practice medical advisors, and senior complaints managers had responsibility for managing poor performance of general practitioners (GPs)

- Local medical committees: the statutory representative body for GPs, who are independent contractors to the NHS. Medical secretaries have a responsibility for supporting and handling poorly performing GPs

- Trust hospitals: medical directors and senior complaints managers have responsibility for managing problem doctors

- Community health councils: the statutory bodies representing the views of patients in the NHS. Chief officers, who are employed through NHS funding, act as the patient's representative in complaints over a doctor's performance.

All UK health authorities/boards and local medical committees were included in the survey, together with a random sample of approximately $50 \%$ of hospital trusts and $50 \%$ of community health councils. Participants in the development of the questionnaire and those in health authorities in the North West NHS region who had been closely involved in developing management guidance for the NHS on handling poorly performing GPs were excluded from the study.

Survey questions were identified through 48 semistructured interviews, the framework for which was drawn from published research, and six exploratory interviews. The resulting areas of interest in the questionnaire were:

- Recipients awareness of the performance procedures: did the respondents know about the performance procedures and from whom had they obtained the information?

- Recent experience of using informal methods of handling poor medical performance: which methods had been most frequently used by respondents? These methods were synthesised from the literature, especially from Rosenthal ${ }^{1}$ (box 4)
(1) Informal discussion
(2) Work shifting
(3) Diverting patient flow
(4) Assigning easier cases
(5) Exporting the problem
(6) Additional education and training
(7) "Three wise men"
(8) Informal involvement of LMC

Box 4 Procedures for assessing poor performance

- Extent and character of poor performance encountered recently: what types of poor performance had been most commonly encountered?

Table 2 Number of respondents who encountered specific performance problems in the previous two years in general practice and hospital practice, ranked by frequency of experience of problem (\%)

\begin{tabular}{|c|c|c|c|c|c|}
\hline \multicolumn{3}{|l|}{ General practice } & \multicolumn{3}{|l|}{ Hospital practice } \\
\hline $\begin{array}{l}\text { Health authority; } \\
n=134\end{array}$ & $\begin{array}{l}\text { Community health } \\
\text { council; } n=67\end{array}$ & $\begin{array}{l}\text { Local medical } \\
\text { committee; } n=73\end{array}$ & $\begin{array}{l}\text { Health authority; } \\
n=134\end{array}$ & $\begin{array}{l}\text { Community health } \\
\text { council; } n=67\end{array}$ & Trust; $n=182$ \\
\hline Manner and attitude & Manner and attitude & Manner and attitude & Manner and attitude & Manner and attitude & Manner and attitude \\
\hline $119(89)$ & $63(94)$ & $63(86)$ & $58(43)$ & $65(97)$ & $167(92)$ \\
\hline Communication & Communication & Communication & Communication & Communication & Communication \\
\hline $110(82)$ & $63(94)$ & $54(74)$ & $58(43)$ & $65(97)$ & $166(91)$ \\
\hline $\begin{array}{l}\text { Management and } \\
\text { outcome }\end{array}$ & Diagnosis & Diagnosis & $\begin{array}{l}\text { Management and } \\
\text { outcome }\end{array}$ & $\begin{array}{l}\text { Management and } \\
\text { outcome }\end{array}$ & $\begin{array}{l}\text { Management and } \\
\text { outcome }\end{array}$ \\
\hline $98(73)$ & $59(88)$ & $48(66)$ & $47(35)$ & $61(91)$ & $129(71)$ \\
\hline Prescribing & $\begin{array}{l}\text { Management and } \\
\text { outcome }\end{array}$ & Prescribing & Diagnosis & Diagnosis & Diagnosis \\
\hline $96(72)$ & $52(78)$ & $45(62)$ & $42(31)$ & $60(90)$ & $91(50)$ \\
\hline Diagnosis & Prescribing & $\begin{array}{l}\text { Management and } \\
\text { outcome }\end{array}$ & Prescribing & Prescribing & Prescribing \\
\hline $92(69)$ & $47(70)$ & $44(60)$ & $35(26)$ & $38(57)$ & $71(39)$ \\
\hline
\end{tabular}




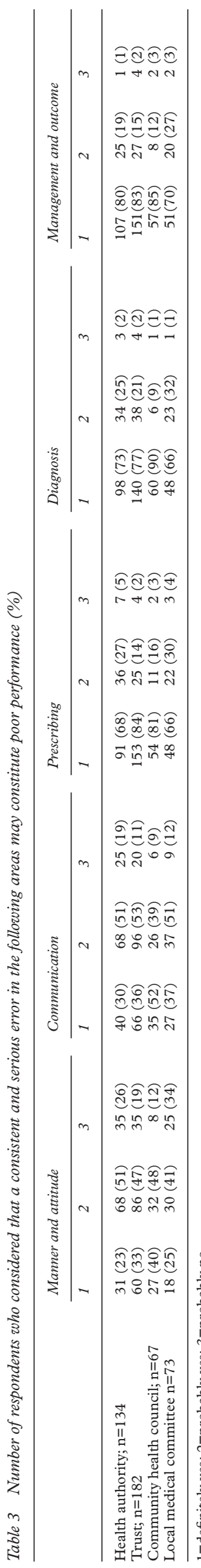

- Definition of poor performance: based on types of poor performance identified in the research literature, what was the perception of the importance of differing types of persistent errors in clinical practice?

- Experience of use of, or preparation for, the procedures: an early attempt to identify the local responses to the implementation of the performance procedures.

The same questionnaire was sent to all respondents, who were asked to comment, where their experience allowed, on practice across the whole spectrum of the NHS, both general practice and hospital practice. In some cases it was only possible for respondents to comment on one of these two areas of practice, and the analysis takes account of these responses.

Addresses for the questionnaires were available for all of the institutions from public documents or, in the case of local medical committee secretaries, by permission of the British Medical Association. A total of 949 questionnaires were sent to 104 local medical committee secretaries, 127 community health council chief officers, 102 health authorities (a questionnaire each to directors of public health, GP medical advisers, and complaints managers, 306 in total), and 206 trusts (medical directors and complaints managers, 412 in total). Reminders were sent to non-responders after three weeks.

Results were postcoded, entered onto an Excel database, and analysed using SPSS. More than one respondent was chosen in trusts and health authorities because it was uncertain who might have lead responsibility for handling poor medical performance and because it enabled access to various different perspectives on the problem. Usually, the addressee returned the questionnaire. In many cases, however, institutions made one return as a matter of policy. The analysis was able to identify which type of staff returned questionnaires and sufficient information from different types of staff was available for subgroup analysis.

\section{Results}

In total, 457 questionnaires were available for analysis, a $48 \%$ response rate overall, mainly from clinicians ( $68 \%$ of respondents). Of the clinical respondents, $72 \%$ were providing regular care for patients across the whole range of specialties and general practice. Although there were responses from more than one type g of health professional in health authorities/ boards and in trusts, there were no significant differences between results from different types of respondent within institution type. Results are therefore displayed by institution type.

The overall response rate of institutions was $68 \%$. Analysed by institution that gave at least one response, the response rate was: health authorities/boards $75 \%$, trusts $69 \%$, local medical committees $71 \%$, community health councils $56 \%$.

In each main section of the analysis, results are displayed from the four types of institution because they each have different aspects of poor performance as their priority and may therefore be expected to have experience and opinions of poor medical practice.

AWARENESS OF THE PERFORMANCE PROCEDURES All of the respondents had heard of the performance procedures, the principal source of information being the GMC itself.

EXPERIENCE OF HANDLING POORLY PERFORMING DOCTORS

Respondents were asked whether they had used any informal mechanisms listed in box 3 to handle a poorly performing doctor over the previous two years.

\section{Informal mechanisms}

Table 1 indicates that an informal discussion was one of the most frequently used informal mechanisms with $82 \%$ of local medical committee respondents, $90 \%$ of trust respondents, and $89 \%$ of health authority respondents using it on at least one occasion in the previous two years. Providing additional education and training was also a frequently used informal mechanism, as was work shifting (a mechanism which involves relieving the poorly performing doctor of some patients/clinical duties). The remaining mechanisms, for example assigning easier cases or exporting the problem, were used less frequently. Only $15 \%$ of health authority and $18 \%$ of trust respondents had assigned easier cases to a poorly performing doctor.

\section{Formal mechanisms}

Respondents were asked about the formal mechanisms they used to handle poor performance, with $67 \%$ of health authority respondents, $57 \%$ of trust respondents, $76 \%$ of community health council respondents, and $58 \%$ of local medical committee respondents having used the existing NHS complaints procedure on at least one occasion in the previous two years. Existing disciplinary procedures had been used slightly less frequently, with almost half of the trusts, community health councils, and local medical committees, and $60 \%$ of the health authority, respondents using them on at least one occasion. Fifty five per cent of health authorities, $43 \%$ of community health councils, $40 \%$ of local medical committees, and $19 \%$ of trusts had referred to the GMC health procedures or to conduct procedures on at least one occasion in the previous two years.

\section{TYPES OF PERFORMANCE PROBLEMS}

ENCOUNTERED

Respondents were asked whether they had encountered specific types of performance problems in the previous two years. The most frequently encountered performance problems were related to consultation skills (table 2). Health authority respondents answered this question less frequently about hospital practice because the problem of poor performance is usually a matter for the trust.

\section{Perceptions of poor performance}

Respondents were asked whether, in their opinion, a consistent and serious error in any 
one of five areas of clinical practice would constitute poor performance (table 3). Almost all respondents stated definitely yes or yes when considering prescribing, diagnosis, and outcome. Respondents were less certain, however, about clearly defining consultation skills of manner and attitude and communication as poor performance despite stating that these are the most frequently encountered performance problems (table 2).

\section{Management of doctors with serious and consistent errors of performance}

Respondents were asked:

- Should a consistent and serious error in any one of (several) areas trigger a local investigation? and

- If that local investigation fails to resolve poor performance, should referral under the GMC performance procedures be considered?

Results showed a similar pattern to those from the perceptions of poor performance questions about the relative importance attached to specific areas of practice. For example, respondents in $51 \%$ of health authorities and $47 \%$ of trusts said probably yes to considering whether to trigger a local investigation for manner and attitude whereas respondents in $80 \%$ of health authorities and $83 \%$ of trusts said definitely yes when considering clinical management and outcome. In the case of referring unresolved performance problems to the GMC, a similar pattern emerged. Respondents showed more reservations about referring serious and consistent errors in relation to the consultation skills of manner and attitude and of communication than about referring poor technical skills.

\section{Discussion}

These results form an important baseline for what is perceived to be good medical practice by senior staff in the NHS, against which it will be possible to assess changes in the local handling of poorly performing doctors. In particular the results show that there is a difference in the perceptions of what constitutes poor practice between consultation skills and what might be termed technical skills, even though problems with consultation skills are far more frequently encountered by the study respondents.

Two of the 14 criteria on good medical practice published by the $\mathrm{GMC}^{9}$ are particularly pertinent here (box 2). Doctors are required to "listen to patients and respect their views" and to "give patients information in a way they can understand". Despite this clear guidance there still seems to be a reluctance to consider doctors as performing poorly if they persistently fail to meet these criteria.

On the basis of this study, mechanisms for the current handling of poorly performing doctors seem rather fragile. Exporting problems or work shifting to colleagues, rather than managing the problem explicitly, may not be in the best interests of patients, employing organisations, or the doctor concerned. It may be that informal mechanisms are in many cases the most appropriate method of handling the poorly performing doctor, but at the very least these mechanisms require a means of ensuring appropriate outcomes. Although the study found that doctors and managers from all parts of the NHS were well informed about the performance procedures it did not follow that appropriate mechanisms were in place to deal with those cases where there are serious concerns over performance. Although no data have been gathered on the outcomes of the informal and formal methods used by respondents to manage poor performance, it is unlikely that these outcomes will be other than those reported by the contributors to the work of Lens and van der Wal, ${ }^{2}$ nor different from that which led to the introduction of the performance procedures. ${ }^{10}$

Nevertheless, it is apparent from the results that most of the respondents ascribed to high standards and expectations of technical competence. The sense of frustration in not being able to deal adequately with the types of performance problems so graphically described in Rosenthal's work, ${ }^{1}$ may be exacerbated by these high professional standards.

Variation from the norms of good medical practice and persistently poor practice are a concern to local clinicians and managers as well as to regulators and policy makers. When this study was undertaken there was relatively little evidence of preparation by institutions to ensure that they were in a position to use the performance procedures effectively or to put in place mechanisms for early diagnosis and more effective management of poor performance. However, data were collected up to six months before the policy and practice changes arising from the recently highly publicised "Bristol case" (in which three doctors had restrictions to practice placed on them for failures in the standards of good practice), recent guidance from the GMC,${ }^{89}$ and the NHS quality initiative. ${ }^{12}$

Responses to these influences may have accelerated change. After the introduction of the performance procedures, Rotherham and colleagues ${ }^{18}$ produced advice for local managers in health authorities in the case of GPs whose performance gave cause for concern. Many local clinical governance committees are attempting to determine how they should handle poor performance within their brief of quality improvement and risk reduction.

But it should be recognised that the dissonance among professionals in the perception of what constitutes poor performance of a doctor in consultation, in contrast with the more technical aspects of care, is a challenge to patient care and perhaps, ultimately, to medical professional self regulation. Changes in societal attitudes to doctors who are rude or unhelpful are likely to mean that, in the future, failures of consultation skills are as likely as failures in technical skills to bring a doctor to the attention of local NHS management, and will require clearer mechanisms for handling poor performance. For this situation to be improved, a more positive approach to acknowledging the rights of patients will be required, particularly at all levels of education and training in medical schools and in the NHS.

The information from this study will now be used in a second investigation which will examine the mechanisms for handling poorly 
performing doctors in the NHS and the use of referral to the GMC performance procedures in those cases where local handling is deemed to have failed.

Thanks are due to the many NHS professionals who contributed to the survey. Our thanks also to the GMC performance procedures evaluation group who provided valuable comments on the study design and on drafts of this paper. Catherine Grinold provided much valued assistance in the presentation of tables. Funding for this study was provided by the GMC and by the Policy Research Programme of the Department of Health.

This research was funded jointly by the GMC and the Department of Health Policy Research Programme.

Allen Hutchinson is a member of the GMC performance procedures evaluation group which commissioned the research project.

Copies of the questionnaire are available from the School of Health and Related Research, University of Sheffield, Regent Court, 30 Regent Street, Sheffield S1 4DA (tel: 0114222 0811).

1 Rosenthal MM. The incompetent doctor. Buckingham: Open University Press, 1995.

2 Lens P, van der Wal G. Problem doctors. Amsterdam: IOS Press, 1997

3 Donaldson LJ. Doctors with problems in a hospital workforce In: Lens P, van der Wal G. Problem doctors. Amsterdam: IOS Press, 1997.
4 Lens P, van der Wal G. Malfunctioning of specialists in dutch hospitals. In: Lens P, van der Wal G. Problem doctors. Amsterdam: IOS Press, 1997.

5 Shafer RD. Legal framework for medical malpractice in Germany. In: Lens P, van der Wal G. Problem doctors. Amsterdam: IOS Press, 1997

6 Dubois O, Haehnel P. When the doctor is ill. In: Lens P, van der Wal G. Problem doctors. Amsterdam: IOS Press, 1997.

7 Maher VF. The US response to problem physicians. In: Lens P, van der Wal G. Problem doctors. Amsterdam: IOS Press, 1997.

8 General Medical Council. Maintaining good medical practice. London: GMC, 1998.

9 General Medical Council. Good medical practice. London: GMC, 1998

10 Department of Health. The medical (professional performances) act (1995). London: DoH, 1995.

11 Dyer C. BMJ News. Study identifies why child heart operations go wrong. BMf 1999;319:803.

12 Department of Health. The new NHS. London: DoH, 1997. 3 Department of Health. A first class service. London: DoH, 1998.

14 Warden J. Hospital death rates to be published for England. BMF 1998;316:1767.

15 Smith R. All changed, changed utterly. BMf 1998;316: 1917-8.

16 Klein R. Competence, professional self regulation, and the public interest. BMF 1998;316:1740-2.

17 Irvine D. The performance of doctors. II: Maintaining good practice, protecting patients from poor performance. $B M \mathcal{F}$ 1997;314:1613-4.

18 Rotherham G, Martin D, Joesbury H, et al. Measures to assist GPs whose performance gives cause for concern. London: Department of Health, 1997. 